\title{
A PRODUÇÃO DAS VOGAIS FRONTAIS ARREDONDADAS DO FRANCÊS (L3) POR FALANTES NATIVOS DO PORTUGUÊS (L1) COM INGLÊS COMO L2: UMA ANÁLISE COM BASE NA TEORIA DA MARCAÇÃO DE CALABRESE (2005)
}

\author{
THE PRODUCTION OF FRENCH FRONT ROUNDED VOWELS BY \\ SPEAKERS OF BRAZILIAN PORTUGUESE (L1), ENGLISH (L2) AND FRENCH (L3): \\ AN ANALYSIS BASED ON THE MARKEDNESS THEORY BY CALABRESE (2005)
}

\author{
Ana Carolina Moura Pompeu ${ }^{23}$
}

\begin{abstract}
RESUMO: De acordo com a Teoria da Marcação de Chomsky e Halle (1968), há nos sistemas fonológicos segmentos marcados e segmentos não-marcados em função dos traços que os compõem. A marcação dos elementos que constituem um sistema determina a complexidade de um sistema em relação a outro. A Teoria da Marcação de Calabrese (2005), que fundamenta este estudo, determina a marcação dos elementos de um sistema através de uma escala de robustez, além de propor alguns Procedimentos de Simplificação aos quais os falantes se firmam ao deparar-se com segmentos complexos (marcados) que não estão presentes no sistema de sua língua materna. Neste estudo, serão investigadas, portanto, a produção das vogais frontais arredondadas do francês, /y/, /ø/ e /œ/, por falantes de português brasileiro (L1) que têm o inglês norte-americano como segunda língua (L2) e o francês como terceira (L3). A partir desta investigação, objetiva-se apontar quais estratégias de reparo (procedimentos de simplificação) serão usadas na produção com falha das três vogais-alvo do francês por 08 (oito) participantes, aprendizes de francês como L3. A análise fonológica dos dados, verificou que os participantes recorreram ao apagamento do traço marcado presente no sistema da L3, substituindo-o por um traço compatível presente no sistema da língua materna.
\end{abstract}

PALAVRAS-CHAVE: Marcação. Aquisição de língua estrangeira. Procedimentos de simplificação.

ABSTRACT: According to the Markedness Theory designed by Chomsky and Hale (1968), in phonological systems some segments are marked and others unmarked depending on the phonological features which compose them. The complexity of a system in relation to another is determined by the marks in the segments that constitute them. The Markedness Theory proposed by Calabrese (2005,) which is the framework of this study, determines the marks in the elements of a system through a robustness scale, in addition, the author, also proposes some Simplification Procedures in which speakers might apply when they face marked segments not present in their mother language. This study will, therefore, investigate the production of rounded front vowels of French, /y/, /ø/ e /œ/, by Brazilian Portuguese speakers (L1) who have American English as a second language (L2) and French as third language (L3). Based on this investigation, we aim to point out which repair strategies (simplification procedures) will be used in the production failure of the three French target vowels by 08 (eight) participants who study French as an L3. The phonological analysis of the data showed that the participants applied the deletion procedure in the marked feature present in the L3 system, replacing it by a compatible feature present in the system of the mother language.

KEYWORDS: Markedness. Foreign language acquisition. Simplification procedures.

\section{Introdução}

No Brasil, existem poucos estudos sobre a aquisição multilíngue. Apesar de residirem no país diversas comunidades de imigrantes bilíngues e multilíngues que poderiam servir de dados para estudos envolvendo a investigação de duas ou mais línguas, tal prática ainda é pouco exercida. No cenário brasileiro, ainda é cultivada a ideia de língua única. Diferentemente, em uma perspectiva global, ser multilíngue não é exceção. Existem muitas regiões bilíngues em vários países europeus, tais como Espanha, Holanda, Finlândia, Suíça e Áustria. Nessas regiões, as gerações jovens estudam inglês como terceira língua (L3). Em

\footnotetext{
${ }^{23}$ Doutoranda em Linguística do Programa de Pós-Graduação em Letras - Escola de Humanidades da Pontifícia Universidade Católica do Rio Grande do Sul - PUCRS. E-mail: anacmpompeu@gmail.com
} 
muitos casos, aprender uma L3 é considerado necessário não somente para os imigrantes, mas para o contato diário.

Juntamente com os estudos de Blank (2008, 2013), Brito (2011) e Pereyron (2017), este estudo traz uma contribuição para a área de aquisição multilíngue referente às transferências fonológicas que podem ocorrer numa situação específica de três línguas, considerando o português como língua materna, o inglês como segunda língua e o francês como terceira língua. Assim, o presente trabalho tem a intenção de fornecer subsídios para a fonologia, bem como para a área de aquisição da linguagem.

A Teoria da Marcação de Calabrese $(1995 ; 2005)$ fundamenta este trabalho no que diz respeito à marcação específica, à complexidade de um segmento em um sistema, assim como a complexidade do próprio sistema fonológico. Calabrese (2005) determina a complexidade de um segmento através de uma escala de robustez em que a presença de traços menos robustos em um sistema implica a presença de traços mais robustos ${ }^{24}$. O autor também sugere que o falante de língua estrangeira utiliza estratégias de reparo ao deparar-se com segmentos que não pertencem ao sistema de sua língua materna.

O objetivo geral deste estudo é analisar as produções do francês (L3) e descrever os dados referentes à parte fonológica dessa língua. A análise fonológica teve como objetivo verificar as estratégias de reparo usadas na produção com falha das três vogais frontais arredondadas do francês, /y/, /ø/ e /œ/, nas produções de 08 (oito) falantes de português brasileiro (L1) que têm o inglês como segunda língua (L2) e o francês como terceira (L3). As três vogais em estudo são elementos marcados para o português e o inglês, ou seja, são inexistentes no sistema fonológico dessas línguas.

A partir da análise fonológica, foi formulada a hipótese de que o procedimento de simplificação ${ }^{25}$ mais usado na produção do francês seria o apagamento de um dos traços da configuração marcada [-post, +arred], pois os sistemas fonológicos com que os informantes estão familiarizados, português e inglês, não possuem vogais com esses traços.

\section{Revisão da literatura}

Calabrese (1995) propõe uma teoria de marcação com base em uma representação arbórea. A marcação da má-formação de um segmento e seu reparo diferencia a teoria de Calabrese (1995) da proposta por Chomsky e Halle (1968) (FESTUGATO, 2005).

Segundo Calabrese (1995), algumas combinações de traços são impossíveis devido às dificuldades articulatórias impostas; por exemplo, um segmento [+alto, +baixo] é impossível de ser articulado pelo homem. Existem as combinações complexas do ponto de vista articulatório e perceptual; por exemplo, os segmentos $[\theta, \delta]$, ([+cont, -estrid]), presentes no inglês são, complexos, de acordo com Festugato (2005: 56), "devido aos ajustes articulatórios necessários para manter a ausência de estridência em fricativas".

A complexidade acústico/articulatória de uma dada combinação de traços, a que Calabrese (1995) chama de condição de marcação, marca a ocorrência de um dos traços do contexto como complexa. A condição de marcação é explicitada através de um traço marcado (sublinhado) como no exemplo: [-post, +arr] / [ _, -bx], isto é, o traço arredondado é marcado para vogais com os traços [-post] e [-bx]. As condições de marcação identificam configurações fonológicas complexas que podem ser encontradas em alguns inventários fonológicos. Essas condições implicam um custo para configurações fonológicas específicas. Muitas são as línguas que não possuem vogais frontais arredondadas pelo custo que a condição de marcação *[-post, +arred] acarreta.

\footnotetext{
${ }^{24}$ Uma maior descrição desta proposta será apresentada na seção "Revisão da Literatura".

${ }^{25}$ Os Procedimentos de Simplificação serão descritos na seção de mesmo nome.
} 
Os segmentos caracterizados por uma configuração mencionada em uma dada condição de marcação ocorrem em uma língua, se e somente se, a condição de marcação relevante for desativada. Se uma condição de marcação estiver ativa, o segmento relevante é descartado do sistema. Quanto mais condições de marcação são desativadas, mais complexo fica o sistema.

Na teoria de Calabrese (1995), nem todas as combinações de traços têm o mesmo grau de complexidade, pois algumas são mais complexas que outras e, portanto, mais difíceis de serem encontradas nas línguas, o que está representado hierarquicamente na árvore seguinte:

Figura1 - Representação arbórea proposta por Calabrese (1995).

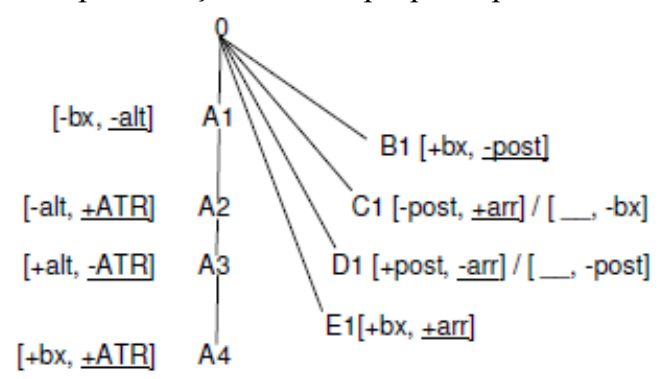

Fonte: Calabrese (1995:381)

Nesta teoria, a complexidade de cada configuração está relacionada com a distância do ramo em relação ao ponto zero. Em outras palavras, quanto maior a distância do ramo em relação à raiz, maior o grau de complexidade da configuração e, consequentemente, menor a frequência do segmento nas línguas do mundo. Assim, podemos dizer que A4 e E1 possuem o maior grau de complexidade nessa árvore e representam os segmentos de menor frequência nas línguas.

No ramo A, a desativação de uma configuração mais distante da raiz acarreta a desativação de todas as configurações acima do referido ramo. Em outras palavras, quando desativada, por exemplo, a configuração A3, também serão desativadas as configurações A1 e A2.

Em 2005, Calabrese reformula a proposta de marcas da figura 1 com base na escala de robustez de Clements (2004). Calabrese (2005) passa, então, de uma proposta arbórea de hierarquia fixa para uma hierarquia gradiente. O autor afirma que, na robustez, os traços mais robustos são mais explorados do que os menos robustos, enfatizando o que está implícito na árvore. Isso quer dizer que a presença de traços menos robustos em um sistema implica a presença de traços mais robustos.

Figura 2 - Escala de robustez proposta por Calabrese (2005).

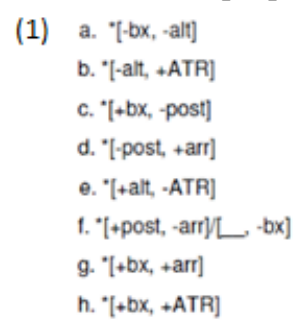

Fonte: Calabrese (2005:127)

A proposta de Calabrese (2005) dispõe as condições de marcação em uma escala hierárquica em que o traço marcado é sempre o menos robusto à direita do par de traços da configuração, desfazendo a necessidade do sublinhado.

Em Calabrese (2005), o segmento mais marcado é aquele representado pela configuração mais afastada do ponto inicial (1a). Assim, a condição de marcação (1h) 
representa o segmento mais marcado de toda a escala, ou seja, aquele menos frequente nas línguas do mundo, enquanto a condição de marcação (1a) representa o segmento menos marcado da escala. Pode-se dizer, então, que a complexidade de cada configuração está diretamente relacionada com sua posição na escala.

A escala de marcas atual permanece com a ideia de complexidade expressa por árvore. Os segmentos caracterizados por uma combinação de traços mencionada em uma condição de marcação ocorrem em dada língua se e somente se a condição de marcação for desativada. Consequentemente, a inserção de um segmento marcado em um sistema provoca um custo para a língua, ocasionando o aumento de complexidade.

Segundo Calabrese (2005: 129), uma língua em que nenhuma condição de marcação é desativada apresenta o sistema vocálico exemplificado em (2a), abaixo. O árabe é citado como exemplo. Se uma língua desativar a condição de marcação $(1 \mathrm{c}) *[+\mathrm{bx}$, -post], terá o sistema (2b), do Letão, segundo Calabrese. Se uma língua desativar a condição de marcação (1a), *[-bx, -alt], inserem-se no sistema os segmentos /E/ e /o/, sistema (2c) do Grego Moderno, Espanhol, Havaiano e outras línguas. Se, além de (1a), uma língua desativar a condição de marcação (1b), mais duas vogais são inseridas, como em (2d). O Italiano e o Português são exemplos. Se a condição de marcação desativada for (1c) e (1d), que representam respectivamente as configurações [+bx, -post] e [-post, +arr], acrescentam-se ao sistema as vogais /æ/, /ü/ e /ö/ representadas no sistema (2e), que o Finlandês exemplifica.

Figura 3 - Sistema vocálico árabe (a), letão (b), grego moderno, havaiano e espanhol (c), italiano e português (d) e finlandês (e).

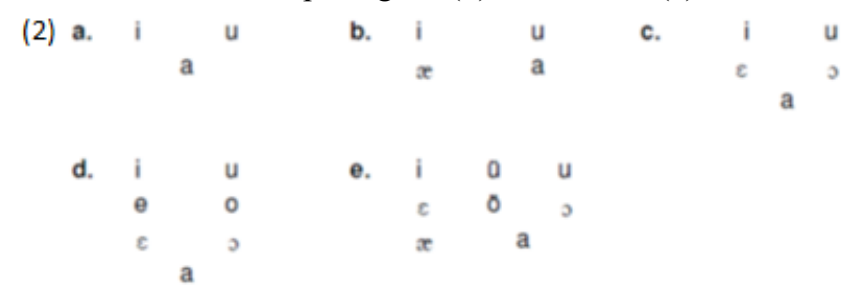

Fonte: Calabrese (2005:129)

Ao apontar maior ou menor complexidade de um sistema, a teoria de Calabrese (2005), tanto em forma de árvore quanto em forma de escala, é um recurso para explicar as dificuldades encontradas por aprendizes de uma segunda língua, pois na aquisição dessa língua pode ocorrer uma fase de desativação de condições de marcação proibidas pelo sistema da língua materna do aprendiz.

\subsection{Procedimentos de simplificação}

Os aprendizes de língua estrangeira, ao entrar em contato com o sistema fonológico da língua alvo, normalmente deparam-se com fonemas que não fazem parte do inventário fonológico da sua língua materna. Tais fonemas são na língua nativa segmentos marcados, pois não fazem parte do seu sistema. Diante de estruturas marcadas, os aprendizes podem reagir de duas maneiras: aceitam o segmento, desativando a condição de marcação que o caracteriza, ou reagem substituindo-o por um segmento semelhante pertencente ao sistema de sua língua materna. Para isso, valem-se de estratégias denominadas por Calabrese (1995, 2005), de procedimentos de simplificação. Através delas reparam ou eliminam uma configuração marcada, isto é, "muito complexa". Conforme Calabrese (2005), esses procedimentos de simplificação são identificados como apagamento, fissão $e$ negação/excision. 
Por apagamento entende-se o apagamento de um dos traços incompatíveis de uma configuração proibida, que é substituído por um traço compatível. O exemplo é o da vogal/y/ do francês, que é substituída por [i] ou por [u] na pronúncia de falantes que não possuem essa vogal no inventário fonológico de sua língua materna. Em outras palavras, na substituição da vogal /y/ por [i] há o apagamento do traço [+arred] da configuração [-post, +arr] e na substituição de $/ y /$ por [u] há o apagamento do traço [-post] da mesma configuração que é substituído pelo traço [+post].

A Fissão envolve a inserção de um traço e divisão do segmento da configuração marcada em dois traços independentes, formando um ditongo via clonagem dos demais traços. Desse procedimento resulta um ditongo, como no caso descrito pelo autor quando a vogal /y/ é substituída pelo ditongo [ju]. Calabrese (2005) observa que na fissão há a preservação dos traços da configuração do input ilícito na forma do output, mas através da bifurcação da configuração marcada.

Por último, conta-se com a negação/excision, em que nenhum traço da configuração ilícita do input é preservado. Esse procedimento é exemplificado pela produção de [i] por falantes russos no lugar do /y/ do húngaro, em que há a remoção completa de todos os traços da configuração marcada [-post, +arred], substituída pela configuração ótima, [+post, -arred].

\section{Metodologia}

A investigação empírica foi caracterizada por uma pesquisa de campo transversal, realizada com oito participantes, quatro homens e quatro mulheres. É importante destacar que a seleção de informantes de ambos os sexos ocorreu devido à pouca demanda de indivíduos que preencham os requisitos necessários para a realização da pesquisa. Todos os participantes eram falantes nativos do português brasileiro (L1), falantes de inglês como L2 e de francês como L3. Esses informantes apresentavam idade média de 24 anos e foram organizados por tempo de estudo de inglês e francês, todos foram estudantes de cursos particulares de idiomas.

Para participar da pesquisa, os participantes deviam ter no mínimo 4 anos de estudo em inglês e no máximo 2 anos de estudo em francês e nenhum conhecimento de outras línguas estrangeiras que não as estudadas neste trabalho. Tais critérios foram estipulados, pois, segundo Llisterri (1995), o estágio de aquisição de uma L2, a experiência com a língua, o grau de exposição e a idade de aquisição exercem um papel importante na produção e percepção em L2.

Além disso, todos responderam a uma entrevista para aferição de seus conhecimentos e experiências linguisticas e assinaram um Termo de Conhecimento Livre e Esclarecido que apresentava cada uma das etapas da pesquisa.

Para obtenção dos dados foram aplicados três instrumentos de coleta para o francês. O primeiro consistia na leitura de monossílabos em ordem alfabética, o segundo na memorização dos mesmos monossílabos e o terceiro consistia na leitura de frases-veículo. A primeira tarefa em francês contou com um total de 30 palavras (Anexo), sendo que 10 continham a vogal em estudo, /y/, 10 continham a vogal /ø/ e 10 a vogal /œ/. Para esta pesquisa, optou-se por apresentar os itens lexicais em arquivo do tipo PowerPoint, em que cada slide apresentava três, das trinta palavras, uma para cada vogal alvo, e isoladas de um contexto frasal. Por exemplo, bulle, coeur, feu aparecem nesta disposição em um slide. Na segunda tarefa, memorização, as palavras foram apresentadas da mesma forma que no instrumento anterior, com a diferença de ter um slide em branco após o slide com os vocábulos. Ao se deparar com a tela em branco, o informante deveria produzir em voz alta as palavras que memorizou no slide anterior. No último instrumento, leitura de frases, foram selecionadas aleatoriamente 15 das 30 palavras dos instrumentos anteriores. Cada um desses 
vocábulos foi inserido em uma frase-veículo (Le dernière mot est dispostas em um grupo de três por slide.

As palavras que compõem o corpus do francês foram escolhidas aleatoriamente através do dicionário Larousse. O critério adotado para a seleção foi serem monossílabos, com o objetivo de concentrar a produção do informante em apenas uma vogal. Pretendia-se selecionar palavras em que a vogal alvo estivesse inserida em um contexto fonológico de consoantes desvozeadas, pois, segundo Rauber (2006), as consoantes vozeadas podem esconder a identificação precisa do ponto que a vogal começa e termina, durante a análise acústica. No entanto, tal critério não pôde ser adotado, pois houve dificuldade de encontrar palavras monossílabos com as três vogais em francês.

\section{Descrição e análise fonológica}

Com foco nas vogais frontais arredondadas do francês, /y, 凤, œ/, produzidas por falantes de português com domínio de inglês como L2, no processo de aquisição de terceira língua, discutem-se as estratégias de reparo ou procedimentos de simplificação. Como vimos, segundo Calabrese (2005), essas estratégias são usadas pelos informantes quando se deparam com uma configuração marcada, [-post, +arr], por exemplo, ausente no sistema vocálico de sua língua materna e da L2.

\subsection{A vogal /y/}

$\mathrm{Na}$ análise da vogal /y/, verificou-se que os três procedimentos de simplificação, apagamento, fissão e negação, foram utilizados pelos participantes.

A tabela abaixo apresenta um resumo das variantes bem como a frequência em que cada uma foi produzida:

\begin{tabular}{|c|c|c|}
\hline Variante & № de ocorrência & $\%$ \\
\hline [u] & 136 & 68 \\
\hline [i] & 28 & 14 \\
\hline [ju] & 8 & 4 \\
\hline [o] & 2 & 1 \\
\hline [e] & 2 & 1 \\
\hline [e] & 1 & 0,5 \\
\hline$[\varnothing]$ & 1 & 0,5 \\
\hline
\end{tabular}

Fonte: a autora

Como vemos, a vogal $/ \mathrm{y} /$ foi substituída por sete variantes. A variante $[\mathrm{u}]$ foi usada com maior frequência (68\%) do que [i], com 14\% de frequência, enquanto o ditongo [ju] aparece com pouca frequência, 4\%. As demais variantes não apresentaram frequência significativa. De acordo com Furlanettto (1988) e Duran e Corsi (2007), [u, i] são os prováveis erros na produção de /y/. No estudo de Alcântara (1998), que investigou as vogais frontais arredondadas do francês por falantes nativos do português, [u, i, ju] foram as três variantes encontradas na produção do mesmo segmento.

$\mathrm{Na}$ produção da variante $[\mathrm{u}]$ no lugar de /y/, houve o apagamento do traço [-post], que foi substituído por [+post], isto é, por [u], formada pela configuração ótima [+post, +arr], por exemplo, b/y/le $\rightarrow b[u] l e$. Esta configuração é de fácil articulação para qualquer falante, pois é uma vogal constante nos sistemas vocálicos. 
O que podemos afirmar com relação ao emprego de [u] em vez de [i] como estratégia de reparo no lugar de /y/ é a influência da escrita, uma vez que a letra "u" aparece em todas as palavras lidas. Assim, acredita-se que o som /y/ da palavra é lido com o som [u] por influência da escrita.

O português é uma língua cuja relação grafema-fonema é transparente, ou seja, a relação entre letra e som é bastante previsível. No inglês e no francês, essa relação é menos transparente, isto é "a informação fonológica da palavra não é facilmente obtida a partir dos padrões de soletração" (ALVES; BARRETO, 2009: 245). Assim, pode-se inferir que, os informantes, ao usarem o apagamento, neste caso, recorreram à grafia da palavra.

A variante [i] aparece em segundo lugar. Quando da produção dessa variante, há o uso do procedimento de apagamento do traço [+arr] da configuração não permitida, [-post, +arr], que é substituído pelo traço [-arr], formando uma configuração ótima, [-post, -arr], para o sistema do informante.

Tal procedimento foi aplicado às palavras crue, cure, dur e pur, por todos os informantes. Nesse caso, pode-se sugerir que o informante tem consciência de que a vogal alvo é frontal, porém não consegue ajustar o arredondamento dos lábios à vogal [-post].

A última variante usada pelos informantes, e relevante para este estudo, é o ditongo [ju], que por fissão substitui a configuração marcada [-post, +arred], isto é, um segmento marcado, por uma configuração de dois segmentos simples. Segundo Calabrese (2005:391), os dois movimentos articulatórios, arredondamento dos lábios e a posteriorização da língua, necessários para a produção de /y/, tornaram-se sequenciais na produção do ditongo.

Tal procedimento foi usado nas palavras bulle, cure, jupe, lune e tube e por apenas três informantes. No caso da palavra cure, sua semelhança com a palavra do inglês de mesma grafia possivelmente influenciou a produção de um dos informantes, que a produziu de acordo com a pronúncia dessa língua.

Como vimos, para a vogal /y/ obteve-se a produção de sete variantes, [i], [u], [ju], [e], $[\circ]$, [ə] e $[\varnothing]^{26}$. Dentre elas, as três primeiras eram esperadas, de acordo com a teoria de Calabrese (2005) e o estudo de Alcântara (1998), Furlanetto (1988) e Duran e Corsi (2007). As demais variantes, [e], [o], [ə] e [ø], representam a minoria das produções e foram encontradas nos dados de poucos informantes. A seguir, resumimos esses resultados na Tabela $2^{27}$ :

Tabela 2 - Frequência dos procedimentos de simplificação para a vogal $/ y /$.

\begin{tabular}{ccc}
\hline Procedimento & № de ocorrências & $\%$ \\
\hline Apagamento & 168 & 84 \\
Fissão & 8 & 4 \\
Excision & 2 & 1 \\
Corretos & 21 & 10,5 \\
Năo produzido & 1 & 0,5 \\
\hline Total & 200 & 100 \\
\hline
\end{tabular}

Fonte: a autora

A partir da Tabela 2, verifica-se que os três procedimentos esperados, segundo Calabrese $(1995,2005)$, foram aplicados pelos informantes. No entanto, o apagamento foi o procedimento de simplificação mais usado, com $84 \%$ de ocorrência, enquanto os

\footnotetext{
${ }^{26}$ As demais variantes, [e], [o], [ə] e [ø], tiveram baixa ocorrência, 0,5\%, 1\%, 1\% e 0,5\% respectivamente, em relação às variantes descritas acima, e não serão analisadas, aqui, por não apresentarem porcentagem relevante.

27 Deve-se observar que um informante deixou de ler uma das palavras do instrumento.
} 
procedimentos 'fissão' e 'negação' apareceram em poucas produções, $4 \%$ e $1 \%$, respectivamente.

É interessante apontar para o número de produções corretas para essa vogal é de apenas $10,5 \%$. Embora seja a vogal menos marcada, das três estudadas, segundo convenções de Chomsky e Halle (1968), este segmento apresentou a menor porcentagem de acertos. Acredita-se que o conjunto de manobras articulatórias que devem ser realizadas para a produção correta desse segmento, levantamento e anterioridade da língua juntamente com o arredondamento dos lábios, seja um dos fatores que influenciou o baixo percentual de produções corretas para a vogal /y/. Curiosamente, esta foi a vogal que apresentou o menor número de variantes em sua produção.

Pode-se inferir que a influência da grafia e o conjunto de manobras articulatórias que devem ser realizadas na produção da vogal /y/, com as quais o aluno (informante) não está habituado, tenham sido os principais motivadores para as falhas encontradas na produção desse segmento.

\subsection{A vogal /ø/}

Conforme apresentado anteriormente, o segmento /ø/, assim como /y/, é, para o sistema do português e do inglês, formado por uma configuração marcada, isto é, proibida. A condição de marcação *[-post, +arred] fez com que os falantes fizessem uso dos três procedimentos de simplificação na produção de /ø/. O aprendiz de francês deve familiarizarse, no entanto, com essa combinação de traços que no francês tem papel distintivo.

A tabela abaixo apresenta um resumo das variantes, bem como a frequência em que cada uma foi produzida:

Tabela 3 - Frequência das variantes de /ø/.

\begin{tabular}{|c|c|c|c|c|c|}
\hline Variante & $\mathrm{N}^{\circ}$ de ocorrência & $\%$ & Variante & $\mathrm{N}^{\circ}$ de ocorrência & $\%$ \\
\hline [e] & 24 & 12 & [i] & 3 & 1,5 \\
\hline [ह] & 23 & 11,5 & [y] & 3 & 1,5 \\
\hline [o] & 16 & 8 & [œ] & 2 & 1 \\
\hline [u] & 14 & 7 & [og] & 1 & 0.5 \\
\hline [ew] & 11 & 5.5 & [je] & 1 & 0.5 \\
\hline [2] & 11 & 5.5 & [हw] & 1 & 0.5 \\
\hline [ju] & 3 & 1,5 & [oe] & 1 & 0,5 \\
\hline
\end{tabular}

Fonte: a autora

$\mathrm{Na}$ Tabela 3, apresentamos um resumo da frequência das variantes. Observa-se que a variante mais produzida é [e], com $12 \%$ de frequência, seguida da variante [ $\varepsilon$ ] com $11,5 \%$. Como vemos, [e] foi produzida apenas uma vez a mais do que $[\varepsilon]$. A próxima variante, $[o]$, aparece com $8 \%$ de frequência, seguida do [u], com 7\%. Logo após, temos a ocorrência de mais duas variantes, o ditongo [ew] e o schwa, [ə], ambos com 5,5\% de frequência. Com uma diferença significativa entre as produções anteriores, temos a ocorrência do ditongo [ju] e das vogais [i] e [y], com 1,5\% de frequência. Esses segmentos são seguidos por [œ], produzido apenas duas vezes, $(1 \%)$. Por fim, ocorrem quatro ditongos, os quais foram produzidos apenas uma vez (0,5\%): [oc], [je], [cw] e [oe $]^{28}$. Conforme Furlanettto (1988) e Duran e Corsi (2007), [e] e [o] são os erros prováveis quando da produção de /ø/. Alcântara (1998) também encontrou o ditongo [ew].

Passamos, então, para a discussão das variantes deste estudo e dos procedimentos de simplificação correspondentes. Começamos com a variante [e] no lugar de /ø/, em que o traço

\footnotetext{
${ }^{28}$ Esses dados não serão analisados, aqui, por não apresentarem porcentagem relevante.
} 
[+arr] da configuração marcada [-post, +arr] foi apagado e substituído pelo traço [-arr]. Assim, a configuração proibida tornou-se ótima [-post, -arr]. Esse procedimento ocorreu nas palavras: creux, jeu, neutre, noeud, peu, voeu, bleu e meute, por exemplo, $\mathrm{j} / \varnothing / \rightarrow \mathrm{j}[\mathrm{e}]$.

A Tabela 3 mostra que a vogal [e] foi o segmento que mais vezes substituiu a vogal alvo /ø/. A maior ocorrência dessa variante indica que os informantes parecem ter consciência de que a vogal alvo das palavras do instrumento é uma vogal média. Acredita-se que a relação grafema-fonema, citada acima, também possa ter influenciado a produção da variante [e], pois oito das dez palavras que compõem o instrumento possuem o grafema "e" em sua escrita.

A segunda variante mais usada $(11,5 \%)$ foi $[\varepsilon]$, não esperada na produção de $/ \varnothing /$. Conforme o sistema de marcas estabelecido por Chomsky e Halle (1968), a vogal /ع/ é menos complexa do que /œ/. Além disso, conforme Alcântara (1998), os falantes do português tendem a elevar vogais médias, resultando na perda da distintividade entre vogais médiasbaixas e médias-altas, ou seja, há a neutralização do segmento. Diante disso, a contraparte $[\varepsilon]$ foi escolhida. A variante $[\varepsilon]$ aparece na produção das palavras neutre, noeud e meute, por exemplo, $\mathrm{n} / \varnothing /$ tre $\rightarrow \mathrm{n}[\varepsilon]$ tre. Para essa variante, foi aplicado o procedimento de apagamento, pois o traço [+arred] da configuração não permitida foi apagado.

A variante que aparece em terceiro lugar (8\%), de acordo com a Tabela 3, é a vogal [o], que ocorre por apagamento do traço [-post] da configuração marcada [-post, +arred]. O traço apagado é substituído pelo traço [+post], formando a configuração ótima $[+$ post, + arr] que resulta na produção do [o], substituindo a vogal alvo /ø/.

Esse procedimento ocorreu nas palavras: creux, feu, jeu, neutre e peu, por exemplo, $\mathrm{cr} / \varnothing / \rightarrow \mathrm{cr}[\mathrm{o}]$. Nota-se que, nesta substituição, o informante também parece ter consciência do arredondamento da vogal, mas não consegue aplicá-lo à vogal anterior, pois não existe nenhuma vogal anterior com esta característica nos sistemas do português e do inglês. Pode-se dizer que o informante tentou produzir a vogal alvo e tem consciência de sua existência, mas rejeita inconscientemente a presença do arredondamento da vogal [-post].

A produção da vogal $[\mathrm{u}]$ causou estranheza, pois não é uma variante esperada quando da produção de /ø/ (FURLANETTTO, 1988; DURAN; CORSI, 2007; ACÂNTARA, 1998). Tal procedimento ocorreu em palavras como: feu, jeu, neutre, peu, voeu e meute, por exemplo $\mathrm{f} / \varnothing / \rightarrow \mathrm{f}[\mathrm{u}]$. Acredita-se que, mais uma vez, houve a influência da grafia, pois em todas as palavras em que a variante $[\mathrm{u}]$ foi produzida havia a presença do grafema "u".

A última variante cujo número de ocorrência foi significativo é o ditongo [ew], com $5,5 \%$ de frequência. O procedimento usado para formação desse ditongo é fissão. Conforme definição de Calabrese (2005), o principal fundamento dessa estratégia é a preservação dos traços da configuração marcada. Para isso, há a inserção do traço [+post] e a desassociação dos traços [-post] e [+arred]. Pode-se afirmar que a grafia influenciou a produção do ditongo, pois foi realizado em palavras com a sequência de vogais "e" e "u": feu, jeu, neutre e meute.

A variante [ə] foi produzida com a mesma frequência que o ditongo [ew], 5,5\%, nas palavras deux, feu, jeu, peu, voeu, bleu, por exemplo, d/ø/ $\rightarrow \mathrm{d}[ə]$. Nesse caso, o procedimento usado foi a negação, pois houve remoção total da configuração marcada. Verifica-se que os traços da configuração [-post, +arred] foram substituídos pelos seus opostos [+post, -arred].

As próximas variantes são [i], [y], [ju], as quais foram produzidas com a frequência de $1,5 \%$. O segmento [i] foi encontrado na produção nas palavras voeu e $f e u$. A vogal $/ y /$ foi produzida na palavra creux. O ditongo [ju] foi produzido nas palavras neutre e feu. A produção do ditongo [ju] como variante de /ø/ não era esperada, pois não há registro desse segmento em Alcântara (1998), Furlanettto (1988) e Duran e Corsi (2007).

Além das variantes acima citadas, foram encontrados casos em que as vogais /y/ e /œ/ foram produzidas quando da produção falha de $/ \varnothing /$. Esses casos preservam a condição de marcação e mudam a altura da vogal. Não podemos considerar tais ocorrências como 
estratégias de reparo, pois, segundo Calabrese (2005), para isso, deve haver a remoção parcial ou total dos traços da configuração marcada, e observa-se que nenhum desses fenômenos ocorre na produção dessas variantes.

De acordo com a análise acima, na produção da vogal /ø/ foram encontradas quatorze variantes, enquanto Alcântara (1998) encontrou apenas três, [o], [e] e [ew], também presentes neste estudo.

Todavia, observa-se, na Tabela 3, a vogal /ø/ apresentou a maior porcentagem de produções corretas, $41,5 \%$, conforme a Tabela $4^{29}$.

\begin{tabular}{ccc} 
Tabela 4 - Frequência dos procedimentos de simplificação para a vogal /ø/. \\
\cline { 2 - 3 } Procedimento & № de ocorrências & $\%$ \\
\hline Apagamento & 85 & 42,5 \\
Fissão & 18 & 9 \\
Excision & 11 & 5,5 \\
Corretos & 83 & 41,5 \\
Não produzidos & 3 & 1,5 \\
\hline Total & 200 & 100 \\
\hline
\end{tabular}

Fonte: a autora

Em se tratando da vogal $/ \varnothing /$, o apagamento $(42,5 \%)$ foi mais frequente do que fissão $(9 \%)$ e negação $(5,5 \%)$. A frequência do procedimento de fissão na vogal $/ \varnothing /$ aumentou em relação à vogal $/ \mathrm{y} /$.

A quantidade de produções corretas encontrada para a vogal /ø/ pode ser resultado do baixo número de manobras articulatórias feitas para a realização deste segmento. Para a produção correta de /ø/ o arredondamento dos lábios, é o único movimento difícil para os informantes.

Novamente, os principais motivadores da falha na produção da vogal /ø/ são a influência da grafia e a relutância à configuração inexistente no sistema das línguas com que os informantes então familiarizados.

\subsection{A vogal /œ/}

A última vogal a ser discutida é a vogal /œ/. A Tabela 5 apresenta um resumo das variantes, bem como a frequência em que cada uma foi produzida:

Tabela 5 - Frequência das variantes de /œ/.

\begin{tabular}{|c|c|c|}
\hline Variante & $\mathbf{N}^{\circ}$ de ocorrência & $\%$ \\
\hline$[\varepsilon]$ & 95 & 47,5 \\
\hline$[\mathrm{e}]$ & 16 & 8 \\
\hline$[\circ]$ & 16 & 8 \\
\hline$[\varepsilon w]$ & 5 & 2.5 \\
\hline$[\partial]$ & 5 & 2.5 \\
\hline$[\mathrm{o}]$ & 3 & 1.5 \\
\hline$[i \varepsilon]$ & 3 & 1.5 \\
\hline
\end{tabular}

\begin{tabular}{|c|c|c|}
\hline Variante & $\mathrm{N}^{\circ}$ de ocorrência & $\%$ \\
\hline$[\mathrm{u}]$ & 2 & 1 \\
\hline$[\mathrm{\jmath}]$ & 1 & 0,5 \\
\hline$[\mathrm{\varepsilon}]$ & 1 & 0,5 \\
\hline$[\mathrm{u}]$ & 1 & 0,5 \\
\hline$[\mathrm{y}]$ & 1 & 0,5 \\
\hline
\end{tabular}

Fonte: a autora

A vogal em estudo, quando da sua produção falha, foi substituída por doze variantes, dentre elas a vogal $[\varepsilon]$, que aparece com $47,5 \%$ de frequência, tendo sido sugerida como erro provável quando da produção de /œ/ por Furlanetto (1988), Duran e Corsi (2007) e Alcântara

\footnotetext{
${ }^{29}$ Durante a leitura das palavras referentes ao segmento em discussão não foi possível anotar três dados.
} 
(1998). As variantes [e] e [ø] foram produzidas com a mesma frequência, 8\%, valor significativamente distante da primeira colocada. No entanto, a vogal esperada dentre as duas era apenas [ø], a qual também foi encontrada como variante de /œ/ no estudo de Alcântara. A ocorrência de $[\mathrm{e}]$ será discutida mais adiante. As próximas variantes que apareceram foram o ditongo [cw] e o schwa [ə], ambos com a mesma frequência, 2,5\%. Em seguida, temos duas produções com $1,5 \%$ de frequência, o segmento [o] e o ditongo [je]. Com apenas duas ocorrências $(1 \%)$ temos a variante $[\mathrm{u}]$, seguida da vogal [0], com apenas uma ocorrência $(0,5 \%)$, que, segundo os autores referidos, seria uma das vogais prováveis de ocorrer, quando da produção falha de /œ/. Juntamente com essa variante tivemos a produção dos ditongos [oع] e [uc] e da vogal [-post, +arred], /y/.

O segmento $[\varepsilon]$ ocorreu com maior frequência, conforme a Tabela 5. O procedimento de simplificação aplicado na produção dessa variante é o apagamento, pois há o apagamento do traço [+arred] da configuração marcada que, ao ser substituído pelo traço [-arred], forma a configuração ótima, [-post, -arr], por exemplo, c/œ/r $\rightarrow \mathrm{c}[\varepsilon] \mathrm{r}$. Da produção da variante, inferese que os informantes parecem ter consciência da vogal que deve ser produzida nas palavras em questão. Devido à ausência desse segmento nos sistemas do português e do inglês e à falta de treinamento para a desativação da configuração referente à inserção dessa vogal no sistema, os informantes não aplicam o arredondamento. A produção dessa variante confirma os resultados de Furlanettto (1988), Duran e Corsi (2007) e Alcântara (1998).

A segunda variante mais frequente $(8 \%)$ na produção dos informantes deste estudo foi a vogal frontal arredondada do francês, [ø], que será discutida no final desta seção.

A produção da variante [e] no lugar de /œ/ chamou a atenção, pois não ocorreu no estudo dos autores referidos acima. Em contrapartida, esse segmento apresentou a mesma frequência da variante [ø], esperada. Mais uma vez, a mudança de altura parece exercer influência quanto à escolha entre a vogal frontal arredondada média-baixa e a vogal anterior arredondada média-alta. Segundo Alcântara (1998), por se tratar de falantes nativos do português, língua em que há uma tendência à elevação, neste caso de média-baixa para médiaalta, a vogal /ø/ ou a vogal /e/ são preferidas em relação à /œ/. O procedimento usado para a produção de [e] é o apagamento, pois há o apagamento do traço [+arr] da configuração marcada, que é substituído pelo traço [-arr], formando a configuração ótima [-post, -arr], por exemplo, g/œ/l $\rightarrow \mathrm{g}[\mathrm{e}] 1$.

Pode-se dizer que a grafia também tenha interferido na produção de [e] em detrimento da vogal-alvo, uma vez que em todas as palavras em que a variante foi produzida havia o grafema "e" em sua escrita: gueule, jeune, neuf, peur, soeul e voeuf.

A variante [o] prevista como erro provável na produção de /œ/ por Furlanettto (1988), Duran e Corsi (2007) e Alcântara (1998) foi produzida com menor frequência, $(0,5 \%)$, neste estudo.

As variantes [ə] e [ $[\mathrm{w}]$ apareceram com $2,5 \%$ de frequência. O primeiro segmento, [ə], foi produzido, nas palavras jeune e heure, por exemplo, $\mathrm{j} / \mathfrak{œ} / \mathrm{ne} \rightarrow \mathrm{j}[\partial]$ ne. Para essa produção foi usado o procedimento de negação, pois houve remoção total da configuração marcada, [+post, -arred] e substituição por seus opostos.

Na produção do ditongo [ $[\mathrm{W}]$ foi usado o procedimento de fissão, pois houve a criação de um ditongo. Essa variante não se encontra nos resultados dos autores supracitados.

A realização do ditongo [jغ] por /œ/ foi produzida, especificamente, na palavra gueule. A produção dessa variante não tem correspondência com nenhum dos procedimentos propostos pela teoria, especialmente com a fissão, pois há a preservação de apenas um dos traços da configuração marcada, [-post].

A substituição da variante [o] (1,5\%) pela vogal /œ/ não consta nos resultados de Alcântara nem nos erros previstos para essa vogal em Furlanettto (1988) e Duran e Corsi (2007), mas aparece nos dados do presente estudo. A fim de explicar a presença desse 
segmento iremos nos valer das mesmas palavras usadas para explicar a ocorrência da variante [ع] na produção de /ø/. Novamente, a altura parece ter influenciado na produção dessa vogal. Alcântara afirma que os falantes do português tendem a elevar algumas vogais, neste caso, de média-baixa para média-alta. No entanto, na produção da variante [o] houve ainda a tentativa de manter o arredondamento. O procedimento usado para a realização desse segmento é o apagamento. $\mathrm{O}$ traço [-post] da configuração marcada é apagado e substituído pelo traço [+post], por exemplo, g/œ/le $\rightarrow \mathrm{g}[\mathrm{j} \varepsilon]$ le.

A variante $[\mathrm{u}]$ teve $1 \%$ de ocorrência e foi produzida na palavra jeune, $\mathrm{j} / \mathrm{m} / \mathrm{ne} \rightarrow$ $\mathrm{j}[\mathrm{u}]$ ne. $\mathrm{O}$ procedimento usado para a produção dessa vogal é apagamento.

As últimas variantes encontradas, $[\mathrm{w} \varepsilon]$ e $[\circ \varepsilon]$, apresentaram frequência de $0,5 \%$. A grafia parece ter influenciado a produção dessas variantes, pois o primeiro foi produzido na palavra gueule, $\mathrm{g} / \mathrm{a} / \mathrm{le} \rightarrow \mathrm{g}[\mathrm{w} \varepsilon] \mathrm{le}$, e o segundo foi produzido durante a produção da palavra soeur. As sequências "ue" e "oe" das palavras podem ter interferido na pronúncia dos informantes.

Passamos, então, à discussão das variantes [y] e [ø], que se enquadram nos casos de preservação da condição de marcação com mudança de altura. A primeira foi produzida na palavra fleur $(\mathrm{fl} / \mathfrak{\propto} / \rightarrow \mathrm{fl}[\mathrm{y}] \mathrm{r})$, enquanto a segunda foi produzida nas palavras fleur, heure, jeune, neuf, seul e veuf, por exemplo, $\mathrm{fl} / œ / \mathrm{r} \rightarrow \mathrm{fl}[\varnothing] \mathrm{r}$. Esses dois casos também não podem ser considerados estratégias de reparo, uma vez que não houve substituição ou remoção dos traços da configuração marcada [-post, +arred]. A realização de [y] por /œ/ não tem motivação aparente, já a substituição de /œ/ por [ø] parece ser motivada pela dificuldade em delimitar a área entre vogal média-alta e média-baixa. Alcântara (1998) também encontrou tal variante em seus resultados. A altura das duas vogais frontais arredondadas em discussão parece exercer grande influência na escolha entre qual dos segmentos a ser usado. Segundo a autora, a vogal média-alta é preferida em relação à média-baixa em virtude do alçamento das vogais que ocorre no português.

Para a produção da vogal em discussão, assim como para /y/ e /ø/, verificou-se que os três procedimentos de simplificação foram aplicados. A Tabela 6 totaliza a frequência de uso dessas estratégias:

Tabela 6 - Frequência dos procedimentos de simplificação para a vogal /œ/.

\begin{tabular}{ccc}
\hline Procedimento & № de ocorrências & $\%$ \\
\hline Apagamento & 134 & 67 \\
Fissão & 10 & 5 \\
Excision & 5 & 2,5 \\
Corretos & 46 & 23 \\
Não produzidos & 5 & 2,5 \\
\hline Total & 200 & 100 \\
\hline \multicolumn{3}{c}{ Fonte: a autora }
\end{tabular}

De acordo com a Tabela $6^{30}$, observa-se que o procedimento apagamento foi o mais usado quando da produção de /œ/, com $67 \%$ de frequência. Os procedimentos de fissão (5\%) e negação $(2,5 \%)$ não tiveram frequência significativa, assim como nos resultados para as vogais $/ \mathrm{y} / \mathrm{e} / \varnothing /$.

Como vimos, na produção da vogal /œ/ foram encontradas doze variantes, dentre elas, três eram previstas de acordo com Alcântara, $[\varepsilon, \varnothing, ~ \supset]$ e $[\varepsilon$, o] por Furlanettto (1988) e Duran e Corsi (2007). Novamente, a grafia pode ter causado a produção das demais variantes. A

${ }^{30} \mathrm{Na}$ leitura de /œ/, cinco palavras não foram produzidas pelos informantes. 
realização correta da vogal em discussão foi de $23 \%$, isto é, esta é a vogal com o segundo melhor desempenho dentre as três discutidas.

De acordo com as análises, foi possível observar que a grafia e a relutância em desativar a configuração marcada, inexistente nos sistemas ao qual o aluno está habituado, exerceram influência na produção com falhas das três vogais estudadas.

\section{Considerações finais}

As três vogais foco deste estudo, /y/, /ø/ e /œ/, apresentam uma característica que não está presente no sistema fonológico das vogais do português e do inglês, L1 e L2 dos informantes, respectivamente, o arredondamento em vogais frontais, o que pressupõe dificuldades no processo de aprendizagem para falantes do português.

Diante dos resultados expostos nesse estudo, podemos afirmar que o apagamento foi a estratégia mais frequente, seguindo-se a fissão e, por último a negação/excision, corroborando nossa hipótese inicial, pois supúnhamos que o apagamento seria o procedimento de simplificação mais usado. Ao recorrer a esse procedimento, os informantes preservaram o traço marcado da condição de marcação que deveria ser desativada, substituindo-o por um traço compatível de acordo com a definição deste procedimento. Em outras palavras, foi criada uma configuração ótima ao produzir um segmento o qual estavam familiarizados.

Devemos destacar que, paralelamente aos erros, houve, também, realizações bemsucedidas das vogais alvo. Isso nos permite sugerir que os informantes parecem ter consciência da existência das vogais frontais arredondadas no sistema vocálico do francês. Em se tratando de mecanismos de substituição, foi possível assinalar as dificuldades que surgem na aquisição de uma terceira língua, codificando e discutindo os erros encontrados com base na teoria de marcação de Calabrese (2005) e em sua proposta de mecanismos de substituição.

\section{Referências}

ALCÂNTARA, C. O processo de aquisição das vogais frontais arredondadas do francês por falantes nativos do português. Dissertação de Mestrado - UCPel, Pelotas, 1998.

ALVES, U. K.; BARRETO, F. M. O processamento e a produção dos aspectos fonéticofonológicos da L2. In: Lamprecht, R.R. (org). Consciência dos sons da língua, 2009.

BLANK, C. A transferência grafo-fônico-fonológica L2 (francês) - L3 (inglês): um estudo conexionista. Dissertação de Mestrado. UCPel, Pelotas, 2008.

BLANK, C. A influência grafo-fônico-fonológica na produção oral e no Processamento de priming em multilíngues: uma perspectiva Dinâmica. Tese de Doutorado. UCPel, Pelotas, 2013.

BRITO, K. S. Influências interlinguísticas na mente multilíngue: Perspectivas psicolinguísticas e (psico)tipológicas. Tese (Doutorado em Letras). Curitiba: Universidade Federal do Paraná, 2011.

CALABRESE, A. A constraint-based theory of phonological markedness and simplification procedures. Linguistic Inquiry. The Massachussetts Institute of Technology, v. 26, n. 3, p. 373-463, 1995.

. Markedness and economy in a derivational model of phonology. New York (NY): Mouton de Gruyter, 2005.

CHOMSKY, N; HALLE, M. The sound pattern of English. New York, NY: Harper \& Row, 1968.

CLEMENTS, N. Features and Sound Inventories. Symposium on Phonological Theory: Representations and Architecture CUNY, February 20-21, 2004. 
DURAN, G; CORSI, M. S. A Produção dos Fonemas Vocálicos de Alunos Universitários de Língua Francesa: Resultados Parciais. New Sounds 2007: Proceedings of the Fifth International Symposium on the Acquisition of Second Language Speech, 2007.

FESTUGATO, M. M. C. Interferências da língua Talian no aprendizado do espanhol: um estudo de caso. Dissertação de Mestrado. UCPel - Pelotas, 2005.

FURNALETTO, M. M. Francês e português - contrastes e interferências no plano fonológico. In: H.I. Bohn, \& P. Vandressen (Eds.), Tópicos de linguística aplicada: O ensino de línguas estrangeiras (pp. 166-209). Florianópolis: Editora da UFSC, 1988.

LLISTERRI, J. Relationships between speech production and speech perception in a second language. Proccedings of the XIIIth International Congress of Phonetic Sciences. Stockholm, Sweden, 1995.

PEREYRON, L. A produção vocálica por falantes de espanhol (L1), inglês (L2) e português (L3): uma perspectiva dinâmica na (multi) direcionalidade da transferência linguística. Tese (Doutorado em Letras). Universidade Federal do Rio Grande do Sul, 2017. RAUBER, A. S. Perception and production of english vowels by brazilian EFL speakers. Tese de Doutorado. UFSC - Santa Catarina, 2006.

\section{ANEXO}

Palavras usadas nos experimentos de produção oral as vogais do francês (L3).

\begin{tabular}{|c|c|c|}
\hline \multicolumn{3}{|c|}{ Francês } \\
\hline$/ \mathrm{y} /$ & $/ \varnothing /$ & /œ/ \\
\hline bulle & creux & coeur \\
\hline chute & deux & fleur \\
\hline crue & feu & gueule \\
\hline cure & jeu & heure \\
\hline dur & neutre & jeune \\
\hline jupe & noeud & neuf \\
\hline jus & peu & peur \\
\hline lune & voeu & seul \\
\hline pur & bleu & soeur \\
\hline tube & meute & veuf \\
\hline
\end{tabular}

Recebido em 20/06/2019

Aceito em 02/09/2019 